\title{
Efficient maximum common subgraph (MCS) searching of large chemical databases
}

\author{
Roger A Sayle $1^{1 *}$, Jose Batista², J Andrew Grant ${ }^{2}$ \\ From 8th German Conference on Chemoinformatics: 26 CIC-Workshop \\ Goslar, Germany. 11-13 November 2012
}

Despite dramatic improvements in the hardware resources and computational power available to pharmaceutical researchers over the past few decades, the methods used for assessing the 2D chemical similarity between two molecules hasn't changed much since the 1960s. Here we report a novel chemical database search method that allows the exact size of the maximum common edge subgraph (MCES) between a query molecule and molecules in a database to be calculated rapidly. Using a pre-computed index, the 50 nearest neighbors of a query can be determined in a few seconds, even for databases containing millions of compounds. This work builds upon the previous efforts of Wipke and Rogers in the 1980s [1] and of Messmer and Bunke in the 1990s [2], harnessing the advances in high-performance

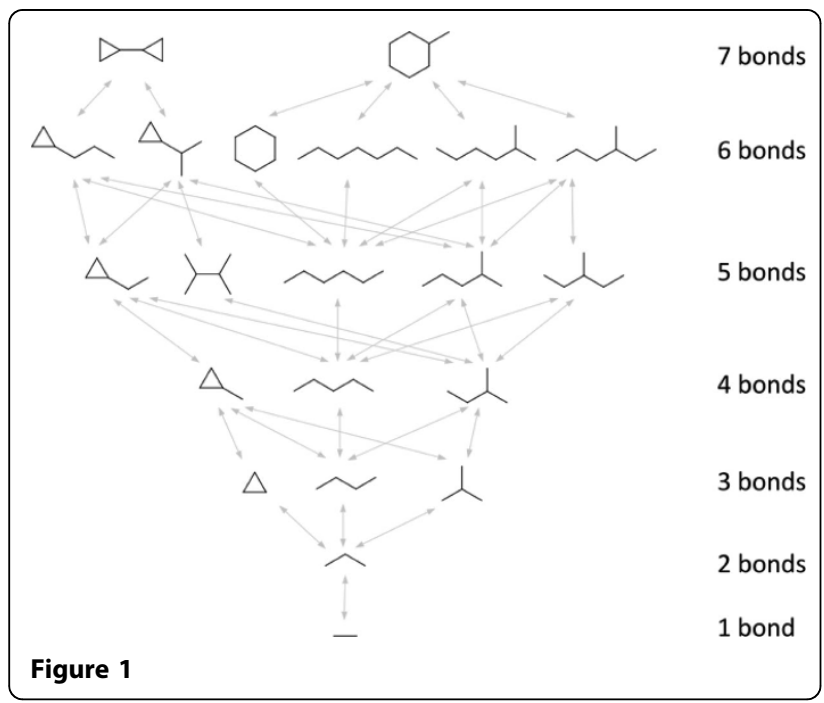

* Correspondence: roger@nextmovesoftware.co.uk

${ }^{1}$ NextMove Software Limited, Cambridge, Cambridgeshire, CB4 OEY, UK Full list of author information is available at the end of the article computing and storage technology now available. A graphical depiction of such a "SmallWorld" index is shown below.

\section{Author details \\ ${ }^{1}$ NextMove Software Limited, Cambridge, Cambridgeshire, CB4 OEY, UK.} ${ }^{2}$ Discovery Sciences, AstraZeneca R\&D, Alderley Park, Cheshire, SK10, UK.

Published: 22 March 2013

\section{References}

1. Wipke WT, Rogers D: Rapid Subgraph Search using Parallelism. J Chem Inf Comput Sci 1984, 24:255-262.

2. Messmer BT, Bunke H: Subgraph Isomorphism Detection in Polynomial Time on Preprocessed Graphs. Proc Asian Conf on Computer Vision 1995, 151-155.

doi:10.1186/1758-2946-5-S1-015

Cite this article as: Sayle et al:: Efficient maximum common subgraph (MCS) searching of large chemical databases. Journal of Cheminformatics 2013 5(Suppl 1):O15.

\section{Publish with ChemistryCentral and every scientist can read your work free of charge \\ "Open access provides opportunities to our colleagues in other parts of the globe, by allowing anyone to view the content free of charge." W. Jeffery Hurst, The Hershey Company. \\ - available free of charge to the entire scientific community - peer reviewed and published immediately upon acceptance \\ - cited in PubMed and archived on PubMed Central \\ - yours - you keep the copyright \\ Submit your manuscript here: \\ http://www.chemistrycentral.com/manuscript/

